\title{
Avian introgression in the genomic era
}

\author{
Jente Ottenburghs ${ }^{1 *} \mathbb{D}$, Robert H. S. Kraus ${ }^{2,3}$ (D, Pim van Hooft ${ }^{1}$, Sipke E. van Wieren ${ }^{1}$, Ronald C. Ydenberg ${ }^{1,4}$
} and Herbert H. T. Prins ${ }^{1}$ (1)

\begin{abstract}
Introgression, the incorporation of genetic material from one (sub)species into the gene pool of another by means of hybridization and backcrossing, is a common phenomenon in birds and can provide important insights into the speciation process. In the last decade, the toolkit for studying introgression has expanded together with the development of molecular markers. In this review, we explore how genomic data, the most recent step in this methodological progress, impacts different aspects in the study of avian introgression. First, the detection of hybrids and backcrosses has improved dramatically. The most widely used software package is STRUCTURE. Phylogenetic discordance (i.e. different loci resulting in discordant gene trees) is another means for the detection of introgression, although it should be regarded as a starting point for further analyses, not as a definitive proof of introgression. Specifically, disentangling introgression from other biological processes, such as incomplete lineage sorting, remains a challenging endeavour, although new techniques, such as the D-statistic, are being developed. In addition, phylogenetics might require a shift from trees to networks. Second, the study of hybrid zones by means of geographical or genomic cline analysis has led to important insights into the complex interplay between hybridization and speciation. However, because each hybrid zone study is just a single snapshot of a complex and continuously changing interaction, hybrid zones should be studied across different temporal and/or spatial scales. A third powerful tool is the genome scan. The debate on which evolutionary processes underlie the genomic landscape is still ongoing, as is the question whether loci involved in reproductive isolation cluster together in 'islands of speciation' or whether they are scattered throughout the genome. Exploring genomic landscapes across the avian tree of life will be an exciting field for further research. Finally, the findings from these different methods should be incorporated into specific speciation scenarios, which can consequently be tested using a modelling approach. All in all, this genomic perspective on avian hybridization and speciation will further our understanding in evolution in general.
\end{abstract}

Keywords: Admixture, Cline theory, D-statictic, Genomic landscape, Hybridization, Phylogenetic discordance

\section{Background}

Introgression is the incorporation of genetic material from one (sub)species into the gene pool of another by means of hybridization and backcrossing (Arnold 2006). For several reasons, it is a common phenomenon in birds: the widespread occurrence of avian hybridization (Ottenburghs et al. 2015) and the slow evolution of intrinsic postzygotic isolation (i.e. hybrids between distantly related species are still fertile), which enables backcrossing, increase the potential for introgression

\footnotetext{
*Correspondence: jente.ottenburghs@hotmail.com

1 Resource Ecology Group, Wageningen University, Droevendaalsesteeg

3a, 6708 PB Wageningen, The Netherlands

Full list of author information is available at the end of the article
}

(Fitzpatrick 2004). Indeed, numerous studies have documented the exchange of genetic material between bird species (Rheindt and Edwards 2011). We searched in Thomson Reuters' Web of Science ${ }^{\mathrm{TM}}$ and Elsevier Scopus ${ }^{\circledR}$ for genetic studies on avian introgression. Our literature search resulted in 165 studies published between 1987 and 2017 (see Additional file 1: Table S1). Publishing studies on avian introgression has not been restricted to ornithological journals. The majority of papers appeared in general journals, indicating that the study of avian hybridization provides insights into broad biological questions concerning evolution and ecology (Fig. 1). Intriguingly, from 2000 onwards, avian introgression studies also start appearing in conservation-orientated journals. This trend is possibly driven 


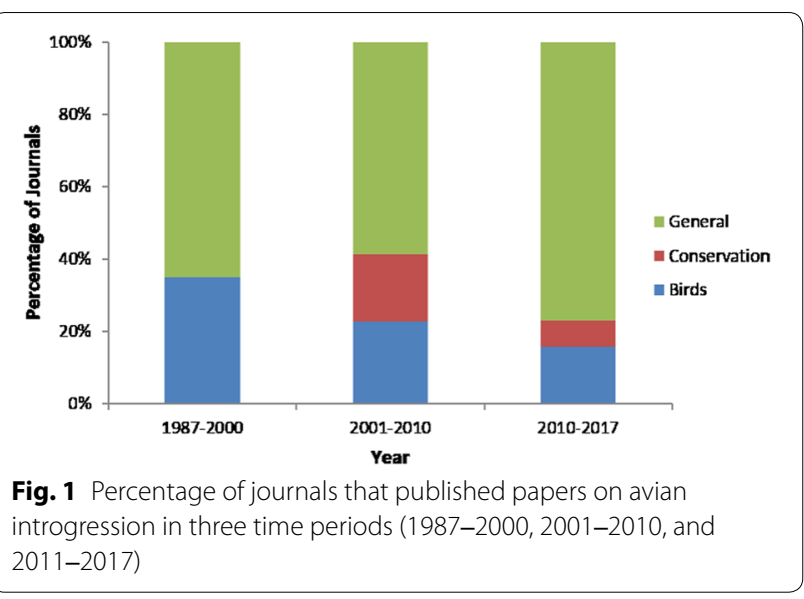

by the Allendorf et al. (2001) paper 'The problem with hybrids: setting conservation guidelines' and emphasizes the importance of understanding avian hybridization in relation to conservation.

Most studies focused on members of the Passeriformes, Galliformes, Anseriformes and Charadriiformes, bird orders that display high levels of hybridization (Ottenburghs et al. 2015). Furthermore, several hybridizing species pairs have become model systems in the study of avian hybridization and introgression: among others, Collared Flycatcher (Ficedula albicollis) and Pied Flycatcher (F. hypoleuca), White-collared Manakin (Manacus candei) and Golden-collared Manakin (M. vitellinus), and Red-legged Partridge (Alectoris rufa) and Chukar Partridge (A. chukar). The study of these model systems mirrors the development of molecular techniques. For instance, the flycatcher system has been studied using mtDNA (Tegelström and Gelter 1990), microsatellites (Saetre et al. 2001), SNPs (Borge et al. 2005) and whole genome data (Ellegren et al. 2012). In general, the toolkit

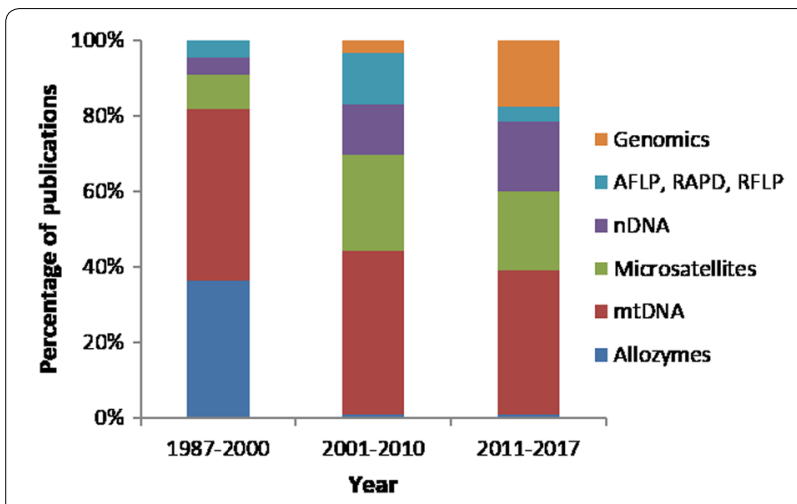

Fig. 2 Use of different genetic markers in studies on avian introgression in three time periods (1987-2000, 2001-2010, and 2011-2017). From 2001 onwards, genomic techniques are being applied. Traditional markers, such as microsatellites and mtDNA, remain popular for studying introgression has expanded over the years, following the progress in molecular markers (Fig. 2).

In this review, we focus on the final step in this methodological progress: genomic data, which has become standard practise in ornithology (Kraus and Wink 2015; Jarvis 2016; Oyler-McCance et al. 2016; Toews et al. 2016). Following Toews et al. (2016), we consider the following next generation sequencing techniques as genomic tools: genome sequencing and resequencing, reduced representation techniques (genotype-bysequencing [GBS] and restriction-site-associated DNA sequencing [RADseq]), sequence capture and RNA sequencing. In this review, we explore how genomic data impacts the different aspects in the study of avian introgression, such as detecting introgression, hybrid zone studies, and the role of introgression in genome architecture.

\section{Detecting hybrids}

One of the first steps in avian hybridization research is the identification of admixed individuals. To tackle this issue several software packages have been developed, such as NewHybrids (Anderson and Thompson 2002), AFLPOP (Duchesne and Bernatchez 2002), BAPS (Corander et al. 2004) and HYBRIDLAB (Nielsen et al. 2006). But the most widely used software package is STRUCTURE (Pritchard et al. 2000). Indeed, 62 out of 87 studies (about 71\%) on avian introgression applied this software package (Additional file 1: Table S1). STRUCTURE uses multilocus genotype data and is based on a clustering algorithm that assigns individuals to populations. Early studies used microsatellites, often in combination with mitochondrial markers (e.g., Barilani et al. 2005). The rapid progress in sequencing techniques introduced the application of SNPs and other genome-wide markers to this method (Saetre et al. 2003; Kraus et al. 2012). A new and updated version, fastSTRUCTURE, allows for the analysis of large SNP datasets (Raj et al. 2014; Elgvin et al. 2017).

STRUCTURE, however popular it remains since over a decade, does have limitations with respect to the underlying population genetic model, such as adherence to Hardy-Weinberg and linkage equilibria (Jombart et al. 2010). Alternatives to STRUCTURE have been developed to address these issues, such as ADMIXTURE (Alexander et al. 2009) and Discriminant Analysis of Principle Components or DAPC (Jombart et al. 2010). Eventually, STRUCTURE, ADMIXTURE and DAPC (and other similar software) are best utilized alongside each other (Frosch et al. 2014). However, all genomic studies in our literature search relied solely on STRUCTURE. 


\section{Phylogenetic discordance}

Hybridization and consequent exchange of genetic material can become apparent in phylogenetic analyses with different loci resulting in discordant gene trees (Degnan and Rosenberg 2009). Hence, this gene tree discordance, also referred to as phylogenetic incongruence, can be used to detect introgression. For example, in a phylogenetic analysis of woodpeckers, Fuchs et al. (2013) attributed conflicting topologies between several loci to an ancient hybridization event between members of the Campephilus and the melanerpine (genera Melanerpes and Sphyrapicus) lineages.

However, introgression is not the only process culminating in phylogenetic incongruence. Other biological processes, such as incomplete lineage sorting and gene duplication, can amount to similar patterns (Maddison 1997; Degnan and Rosenberg 2009). Particularly, incomplete lineage sorting, when lineages fail to coalesce in the ancestral population of two species, seems to be pervasive (Pamilo and Nei 1988). Hence, phylogenetic discordance should not be seen as definitive proof of introgression, but rather as a starting point for further analyses. It is advised to provide other lines of evidence to show that gene tree discordance is the outcome of introgressive hybridization, not incomplete lineage sorting.

One way to discriminate between introgression and incomplete lineage sorting is the Patterson's D-statistic (Durand et al. 2011), a statistical test that was first employed to quantify the amount of genetic exchange between Neanderthals and modern humans (Green et al. 2010). The D-statistic considers ancestral ('A') and derived ('B') alleles across the genomes of four taxa (Fig. 3). Under the scenario of incomplete lineage sorting without gene flow, two particular allelic patterns 'ABBA' and 'BABA' should occur equally frequent. An excess of either ABBA or BABA, resulting in a D-statistic that is significantly different from zero, is indicative of gene flow between two taxa. This approach has been extended to more taxa which allows for identifying the direction of gene flow (Eaton and Ree 2013; Pease and Hahn 2015).

However, an excess of ABBA or BABA can also arise from other processes, such as non-random mating in the ancestral population due to population structure (Eriksson and Manica 2012). Also, the D-statistic was originally developed to infer introgression on a genome-wide or chromosome-wide scale (Green et al. 2010). Calculating this statistic for small genomic regions or specific loci in order to characterize patterns of introgression across the genome can lead to unreliable results, because significant D-statistics tend to cluster in regions of reduced genetic diversity (Martin et al. 2014). It is, therefore, advised to apply the D-statistic for the detection of genome-wide or

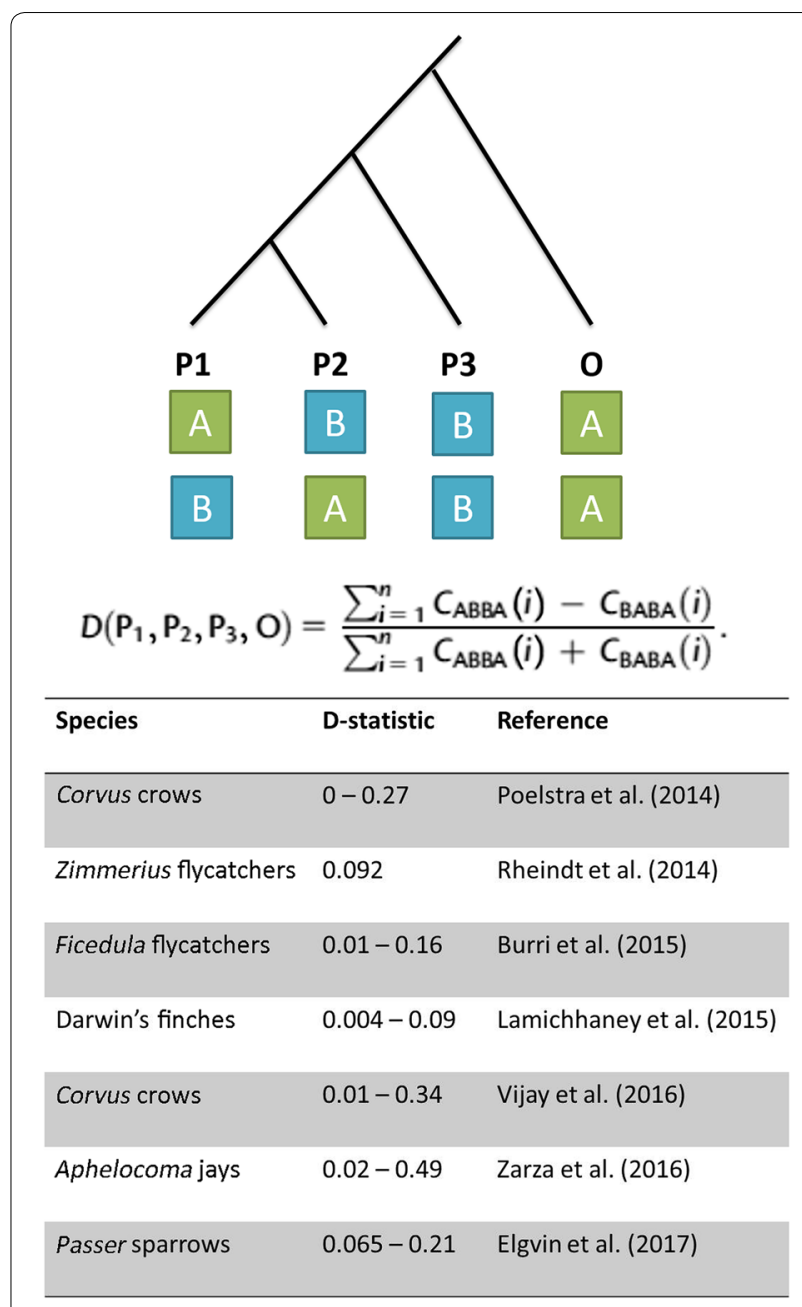

Fig. 3 The D-statistic considers ancestral ('A') and derived (' $B$ ') alleles across the genomes of four taxa. Under the scenario of incomplete lineage sorting without gene flow, two particular allelic patterns 'ABBA' and 'BABA' should occur equally frequent. An excess of either $A B B A$ or $B A B A$, resulting in a D-statistic that is significantly different from zero, is indicative of gene flow between two taxa. The table below shows the range of $\mathrm{D}$-statistics for different bird taxa

chromosome-wide introgression, not to single out possible introgressed regions.

We found five studies on avian introgression that adopted the D-statistic to study introgression patterns in Zimmerius flycatchers (Rheindt et al. 2014), Corvus crows (Poelstra et al. 2014), Darwin's Finches (Lamichhaney et al. 2015), Aphelocoma jays (Zarza et al. 2016), and Passer sparrows (Elgvin et al. 2017). Most studies applied the D-statistic in the appropriate way (i.e. to infer genome-wide introgression), only the study on Zimmerius flycatchers seems to fall into the trap of using the ABBA-BABA-test to pinpoint introgressed loci. In this study, Rheindt et al. (2014) attempt to reconstruct the 
evolutionary history of a phenotypically mosaic population of the Peruvian Tyrannulet ( $Z$. viridiflavus), which shares plumage characteristics with the Golden-faced Tyrannulet (Z. chrysops). Mapping the results from the ABBA-BABA-test to the Zebra Finch (Taeniopygia guttata) genome, they find that some ABBA-favoured SNPs are close to genes involved in cell projection and plasma membranes. Given the connection between cell membranes and plumage coloration, the authors speculate that there might have been introgression of plumage alleles between these populations. However, as discussed above, these loci have not necessarily introgressed, they might represent genomic regions of low genetic diversity due to purifying selection. Examining the level of divergence in putative introgressed regions is recommended here.

Another way to deal with introgression and incomplete lineage sorting is to switch from phylogenetic trees to phylogenetic networks (Huson and Bryant 2006; Ottenburghs et al. 2016, 2017). Some methods for constructing phylogenetic networks allow for hybridization while ignoring incomplete lineage sorting (Beiko and Hamilton 2006), whereas other methods take into account incomplete lineage sorting while ignoring hybridization (Maddison and Knowles 2006; Than and Nakhleh 2009). New methods are being developed to reconstruct phylogenetic networks taking both incomplete lineage sorting and hybridization into account (Joly et al. 2009; Kubatko 2009; Meng and Kubatko 2009; Yu et al. 2013; Wen et al. 2016). This network approach has not been applied to avian genomic data yet, but promises to be a fruitful strategy for the detection of introgression.

\section{Genomic clines in hybrid zones}

Apart from the descriptive nature of detecting introgression, patterns of interspecific genetic exchange can also be used to study the genetics of reproductive isolation and speciation (Harrison and Larson 2014; Payseur and Rieseberg 2016). The extent of introgression of a specific allele depends on several factors, such as hybrid fitness, reproductive isolation and genetic linkage (Barton 1979; Wu 2001; Payseur 2010). Alleles can be roughly divided into three categories: (1) neutral alleles that are free to flow between species, (2) alleles that confer an adaptive advantage and introgress quickly, and (3) alleles that lead to reduced fitness and inhibit gene flow. Hybrid genomes are a mosaic of these three categories, mingled by migration and recombination (Payseur 2010; Wang et al. 2011). Hence, most species boundaries are semipermeable: some genomic regions (e.g., those leading to reduced hybrid fitness) show restricted gene flow while other regions (e.g., comprising neutral or advantageous alleles) are allowed to flow freely.
Hybrid zones, regions where two genetically distinct populations interbreed, are excellent natural laboratories to explore these locus-specific patterns of introgression (Hewitt 1988; Harrison 1990; Harrison and Larson 2016), especially in combination with the application of geographical cline theory (Barton and Hewitt 1985). Cline theory provides a framework to analyse changes in traits or allele frequencies as a function of geographic distance across a hybrid zone transect. Several characteristics of the observed clines can be used to make inferences about hybrid zone dynamics. For instance, cline width in combination with dispersal rates allows for estimation of selection pressures (Barton and Gale 1993). Alleles and traits under similar selective pressures will show concordant cline widths and centres, whereas those subject to different selection pressures will show displaced cline centres compared to the majority of the other clines (Barton 1983).

Numerous avian hybrid zones have been studied using geographical cline theory (Table 1), often combining morphological and genetic data (e.g., Parsons et al. 1993; Gay et al. 2007; Seneviratne et al. 2016). Although geographical cline analysis is a powerful tool to study hybridization and speciation, it has several limitations. First, it assumes a monotonic change in allele frequency across a linear transect, even though hybrid zones can display mosaic and patchy distributions (e.g., Walsh et al. 2016). Second, there is no clear optimal scale for geographical cline analysis and the scale of sampling can potentially influence the results (Gompert and Buerkle 2011). An alternative method that circumvents these limitations is genomic cline analysis, which is based on the frequency of locus-specific genotypes across a genome-wide admixture gradient. Loci that are potentially involved in reproductive isolation can be identified by discordance of genomic clines with a null model (Gompert and Buerkle 2009, 2011; Fitzpatrick 2013).

Characterizing an avian hybrid zone by means of geographical or genomic cline analyses can provide important insights into the genetic underpinnings of reproductive isolation between the hybridizing species. But each hybrid zone study is just a single snapshot of a complex and continuously changing interaction. To capture the dynamic nature of hybrid zones, one can study a particular hybrid zone across different temporal and/ or spatial scales. For example, by comparing historical (2000-2002) and recent (2010-2012) genetic data, Taylor et al. (2014) showed that the hybrid zone between Black-capped Chickadee (Poecile atricapillus) and Carolina Chickadee (P. carolensis) in Pennsylvania has moved north due to changing winter temperatures. However, a temporal comparison is only possible when historical data is available or can be obtained from museum 
specimens (Spurgin et al. 2014; Linck et al. 2017). An alternative strategy is to compare different hybrid zones between the same species (Schaefer et al. 2016; Kingston et al. 2017; Lackey and Boughman 2017). On the one hand, concordant patterns of introgression and differentiation across multiple hybrid zones might pinpoint genes that are important in reproductive isolation or adaptation, regardless of any environmental differences between the hybrid zones. On the other hand, discordant patterns of introgression and adaptation might be used to identify loci under environment-specific selection or drift within the respective hybrid zones. Finally, the spatial comparison of different hybrid zones can be extended to multiple pairs of closely related species. By analysing contact zones between these hybridizing species, patterns of introgression and differentiation can be related to the age of the interacting species, providing insights into the build-up of reproductive isolation and differentiation over time (Grossen et al. 2016; Vijay et al. 2016).

\section{Exploring the genomic landscape}

Genomic data allows researchers to zoom out from locus-specific introgression and differentiation uncovered in hybrid zones and study patterns across the whole genome. Here, genome scans provide a powerful approach (Haasl and Payseur 2016): align the genomes of two species, slide a window across them and calculate a divergence statistic-mostly $F_{\mathrm{ST}}$. The resulting picture is a genomic landscape with islands of differentiated regions in a sea of neutral variation. These islands are commonly referred to as 'differentiation islands' (Harr 2006) or 'speciation islands' (Turner et al. 2005). As the latter term suggests, these islands have often been related to speciation, in particular to the genic view of speciation (Wu 2001) in combination with divergence-with-geneflow (Pinho and Hey 2010). This view holds that divergent selection against gene flow is initially restricted to a few loci. These loci contribute to reproductive isolation and are less likely to introgress compared to selectively neutral loci. Hence, these loci and closely linked genomic regions are expected to diverge while gene flow homogenizes the remainder of the genome (Feder et al. 2012; Via 2012). Furthermore, if genomic islands of divergence are the outcome of reduced gene flow, one expects to find genes contributing to reproductive isolation within them. An alternative explanation for the formation of genomic islands is that they arose through positive and purifying selection (including background selection at linked sites, referred to as 'linked selection') in allopatry, independent of reproductive isolation and gene flow (Cruickshank and Hahn 2014).

The genomic landscape of several avian study systems has been mapped (Table 2). Ellegren et al. (2012) were the first to explore the genomic landscape of divergence in birds. By comparing the genomes of Collared and Pied Flycatcher, they uncovered about 50 'islands of differentiation. These islands were not only characterized by elevated levels of $F_{\mathrm{ST}}$, they also displayed reduced levels of nucleotide diversity, skewed spectra of allele frequencies, and reduced proportions of shared alleles. Combined, these summary statistics are suggestive of selection. Indeed, further exploration of the genomic landscape of flycatchers indicated that the origin of 'islands of differentiation' is mainly driven by linked selection, although heterogeneous gene flow cannot be excluded (Burri et al. 2015). The results from these studies highlight the use of other summary statistics apart from $F_{\mathrm{ST}}$. Most genome scans rely on $F_{\mathrm{ST}}$ to quantify genetic distance along the genome, but $F_{\mathrm{ST}}$ is a relative measure of differentiation that it dependent on the underlying genetic diversity within the population. Other summary statistics provide different perspectives on the processes that sculpted the genomic landscape (Cruickshank and Hahn 2014; Wolf and Ellegren 2017).

If 'islands of differentiation' play a pivotal role in the origin of new species, one expects to find genes involved in reproductive isolation within these islands. This expectation has been confirmed for Carrion Crows (Corvus corone corone) and Hooded Crows (C. c. cornix). A genome scan uncovered a highly differentiated genomic region which contains genes involved in pigmentation and visual perception. This result was further corroborated by differential patterns of gene expression (Poelstra et al. 2014). Genomic analyses of contact zones between other Corvus subspecies (cornix, corone, orientalis and pectoralis) revealed clustering of certain pigmentation genes, albeit in different genomic islands (Vijay et al. 2016). Other studies, however, have shown that genes potentially involved in reproductive isolation do not always cluster together, instead they are scattered across the genome (Parchman et al. 2013; Ruegg et al. 2014; but see Delmore et al. 2015). These contrasting findingscandidate 'speciation genes' clustered in genomic islands versus scattered throughout the genome-suggests that the genetic basis of speciation is highly species-specific and context-dependent.

\section{Future directions}

The approaches discussed above (e.g., phylogenetic discordance, genome scans and genomic cline analysis) are best utilized alongside each other to achieve a complete picture of the speciation and hybridization process. For instance, Parchman et al. (2013) combined genomic cline analyses and genome scans (based on $F_{\mathrm{ST}}$ ) to investigate the Panamanian hybrid zone between White-collared Manakin (Manacus candei) and Golden-collared 

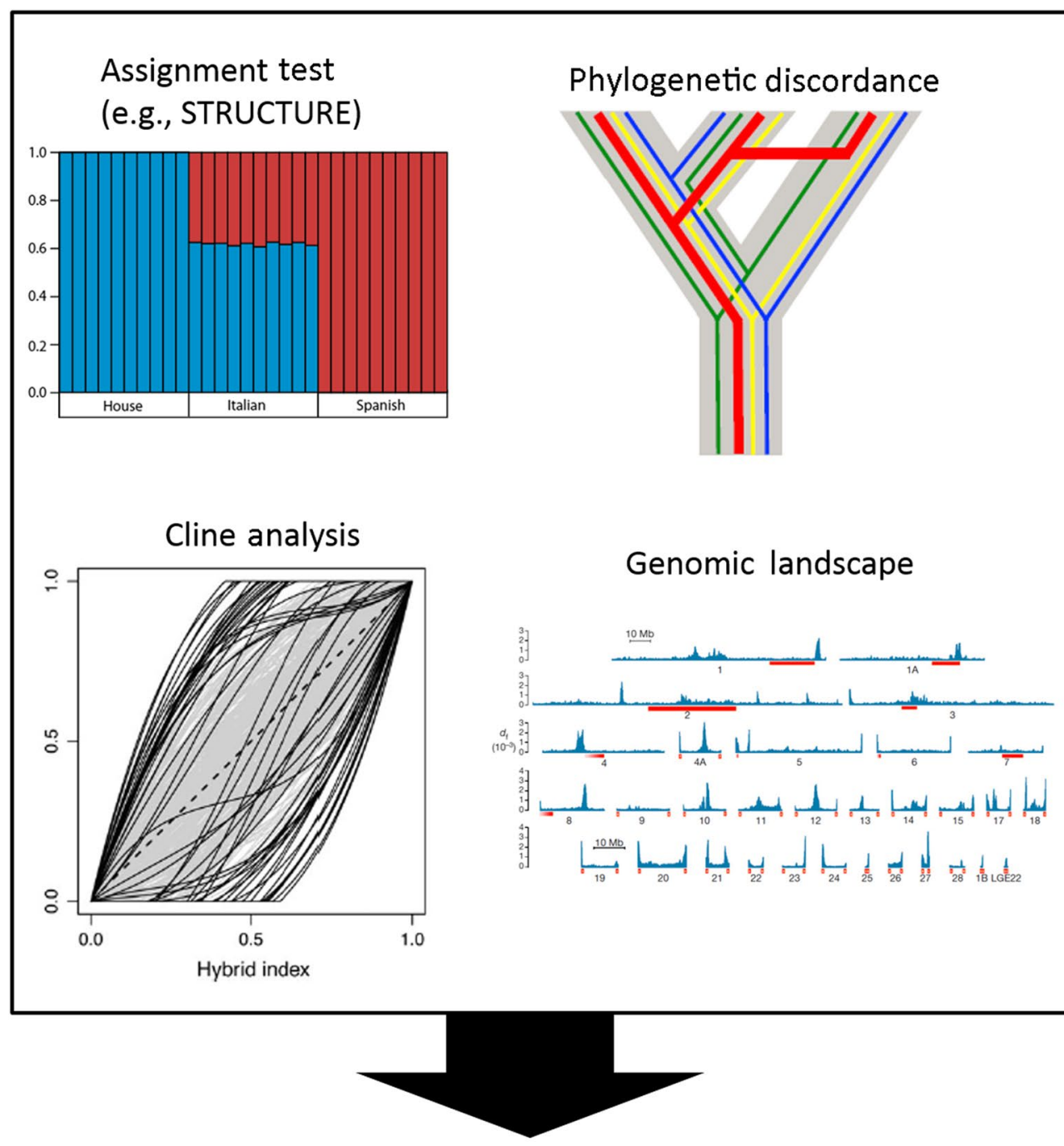

Modelling

(e.g., Approximate Bayesian Computation)

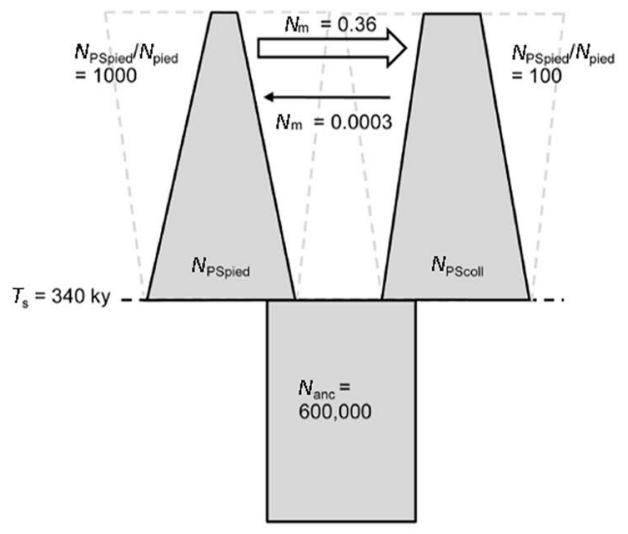

$\mathrm{PP}=0.90$

Fig. 4 The findings from different methods_-admixture test, phylogenetic discordance, cline analysis and genomic islands—can be incorporated into specific speciation scenarios, which can consequently be tested using a modelling approach, such as ABC modelling, which allows for the comparison of different scenarios 
Table 1 Genomic studies on avian hybrid zones

\begin{tabular}{|c|c|c|}
\hline Species & Cline analysis & Reference \\
\hline Manacus candei & \multirow[t]{2}{*}{ Genomic } & \multirow[t]{2}{*}{ Parchman et al. (2013) } \\
\hline Manacus vitellinus & & \\
\hline $\begin{array}{l}\text { Phylloscopus tro- } \\
\text { chiloides } \\
\text { (species complex) }\end{array}$ & Geographic & Alcaide et al. (2014) \\
\hline $\begin{array}{l}\text { Malurus melanocepha- } \\
\text { lus } \\
\text { (subspecies) }\end{array}$ & Geographic & Baldassarre et al. (2014) \\
\hline Poecile atricapillus & \multirow[t]{2}{*}{ Genomic } & \multirow[t]{2}{*}{ Taylor et al. (2014) } \\
\hline Poecile carolinensis & & \\
\hline Sphyrapicus nuchalis & Geographic & Seneviratne et al. (2016) \\
\hline Sphyrapicus ruber & \multirow{2}{*}{$\begin{array}{l}\text { Geographic and } \\
\text { Genomic }\end{array}$} & \multirow[t]{2}{*}{ Grossen et al. (2016) } \\
\hline Sphyrapicus varius & & \\
\hline Pipilo maculatus & \multirow[t]{2}{*}{ Genomic } & \multirow[t]{2}{*}{ Kingston et al. (2017) } \\
\hline Pipilo ocai & & \\
\hline
\end{tabular}

All studies used genotyping-by-sequencing (GBS) to generate the data

Manakin (M. vitellinus). They showed that differentiated loci with high $F_{\mathrm{ST}}$ and loci with discordant clines did not cluster together in the genome. This is in line with the hypothesis that genetic regions involved in adaptive divergence and reproductive isolation are scattered throughout the genome. Most studies on avian introgression, however, relied on one approach (only 58 of the 165 studies [35\%] applied multiple methods).
In addition, findings from different methods can be incorporated into specific speciation scenarios (e.g., allopatric divergence with secondary contact, divergencewith-gene-flow, etc.), which can consequently be tested using a modelling approach (Fig. 4). Several multilocus studies on avian introgression relied on Isolation-withMigration (IM) models to infer gene flow parameters, along with population divergence times and effective population sizes (Hey and Nielsen 2004; Hey 2010; Pinho and Hey 2010). However, these models only estimate the amount of gene flow, not the timing. Furthermore, recent analyses suggested that false positives might be common (Cruickshank and Hahn 2014; Hey et al. 2015). In contrast to IM models, Approximate Bayesian (ABC) modelling does allow for the comparison of multiple scenarios that differ in the amount and timing of gene flow (Beaumont 2010). This way, it is possible to discriminate among distinct speciation scenarios (Yeung et al. 2011; Raposo do Amaral et al. 2013; Nadachowska-Brzyska et al. 2015; Nater et al. 2015; Smyth et al. 2015). Running these models with genomic datasets, while taking into account findings from other analyses, will broaden our understanding of the role of introgressive hybridization in avian evolution.

To discover and describe hybrid zones in the past, many studies relied on 'randomly' sampled specimens, mostly collected within and outside the putative hybrid zone. Sampling strategies that take into account the

Table 2 Avian studies on genomic islands

\begin{tabular}{|c|c|c|c|}
\hline Species & Data & Traits & Reference \\
\hline Ficedula albicollis & WGS & & Ellegren et al. (2012) \\
\hline \multicolumn{4}{|l|}{ Ficedula hypoleuca } \\
\hline Manacus candei & GBS & & Parchman et al. (2013) \\
\hline \multicolumn{4}{|l|}{ Manacus vitellinus } \\
\hline \multirow{2}{*}{$\begin{array}{l}\text { Cathartus ustulatus } \\
\text { (subspecies) }\end{array}$} & GBS & Migration, plumage, and song (-) & Ruegg et al. (2014) \\
\hline & WGS & Migration (+) & Delmore et al. (2015) \\
\hline Anas platyrhynchos & GBS & & Lavretsky et al. (2015) \\
\hline \multicolumn{4}{|l|}{ Anas diazi } \\
\hline 4 species of Ficedula & WGS & & Burri et al. (2015) \\
\hline Corvus corone & WGS & Plumage coloration $(+)$ & Poelstra et al. (2014) \\
\hline (subspecies) & WGS & Plumage coloration (+) & Vijay et al. (2016) \\
\hline 16 species of Darwin's finches & WGS & Bill morphology $(+)$ & Lamichhaney et al. (2015) \\
\hline Sphyrapicus nuchalis & GBS & & Grossen et al. (2016) \\
\hline \multicolumn{4}{|l|}{ Sphyrapicus ruber } \\
\hline \multicolumn{4}{|l|}{ Sphyrapicus varius } \\
\hline Passer domesticus & WGS & & Elgvin et al. (2017) \\
\hline \multicolumn{4}{|l|}{ Passer hispaniolensis } \\
\hline Passer italiae & & & \\
\hline
\end{tabular}

Data were generated by whole genome sequencing (WGS) or genotyping-by-sequencing (GBS). Specific traits under investigation were located within (+) or outside $(-)$ of genomic islands 
resolution of genomic data will need to be developed. Moreover, each hybrid zone study is just a single snapshot of a complex and continuously changing interaction. To capture the dynamic nature of hybrid zones in a genomic context, sampling should be carried out across different temporal and spatial scales.

Due to the increasing amount of genetic data, biology is moving from a hypothesis-driven to a data-driven science. The same pattern can be observed in ornithological research. This shift brings many computational challenges. Most software packages that are routinely used in avian introgression studies (e.g., STRUCTURE, IMa) cannot cope with large genomic datasets (Darriba et al. 2015). Therefore, new computational tools will need to be developed to handle the increasing amount of genomic data. For instance, ExaML, a computationally more efficient version of the maximum likelihood program RAxML, was developed to analyse 48 complete avian genomes (Kozlov et al. 2015). Jarvis et al. (2014) indicated that 'these computationally intensive analyses were conducted on more than 9 supercomputer centers and required the equivalent of $>400$ years of computing using a single processor.'

Apart from developing new computational methods, analyses should be conducted more efficiently. For example, the newest computer hardware technology, such as graphics processing units (GPUs) and multicore central processing units (CPUs), can be implemented to parallelize calculations (Ayres et al. 2011). In addition, new techniques from Artificial Intelligence and deep learning could be applied to 'text mine' genomes which may yield cases of hybridization where we had not expected them (Fogel 2008; Angermueller et al. 2016; Leung et al. 2016).

\section{Conclusions}

In this review, we showed how genomic data can be applied to the study of avian introgression. First, the detection of hybrids and backcrosses has improved dramatically, although the monopoly of STRUCTURE should be broken up by applying other software in concert with it (e.g., DAPC or ADMIXTURE). Another way of detecting introgressive hybridization, phylogenetic discordance (i.e. different loci resulting in discordant gene trees), should be regarded as a starting point for further analyses, not as a definitive proof of introgression. Specifically, disentangling introgression from incomplete lineage sorting remains a challenging endeavour, although new techniques, such as the D-statistic, are being developed. Furthermore, with the advent of genomic data, phylogenetics might require a shift from trees to networks (Edwards et al. 2016; Ottenburghs et al. 2016).

The study of hybrid zones has led to important insights into the complex interplay between hybridization and speciation (Harrison and Larson 2016). Genomic data provide the opportunity to augment the resolution of geographical cline analysis. In addition, genomic cline analysis provides a fresh perspective on hybrid zone dynamics, circumventing several limitations of geographical cline analysis (Gompert and Buerkle 2009). It is, however, important to keep in mind that each hybrid zone study is just a single snapshot of a complex and continuously changing interaction. To capture the dynamic nature of hybrid zones, they should be studied across different temporal and spatial scales.

Genome scans, which uncovered a highly heterogeneous genomic landscape, have become a powerful tool in the genomic toolbox (Nosil and Feder 2012). When performing these genome-wide comparisons, one should realize that there is more to life than $F_{\mathrm{ST}}$. Other summary statistics provide different perspectives on the processes that sculpted the genomic landscape (Cruickshank and Hahn 2014; Wolf and Ellegren 2017). The debate which evolutionary processes underlie the genomic landscape, linked selection or reduced gene flow, is still ongoing. Also, the question whether loci involved in reproductive isolation cluster together in 'islands of speciation' or whether they are scattered throughout the genome remains to be answered. Exploring the genomic landscapes across the avian tree of life represents an exciting field for further research.

Finally, the findings from different methods should be incorporated into specific speciation scenarios, which can consequently be tested using a modelling approach. Especially, the application of ABC modelling, which allows for the comparison of different scenarios, will increase our understanding in avian speciation, which turns out to be more complex than the classical Mayrian triumvirate of allopatric, sympatric and parapatric speciation. Although there are many computation challenges ahead, this genomic perspective on avian hybridization and speciation will further our understanding in evolution in general.

\section{Additional file}

Additional file 1: Table S1. Result of literature search published between 1987 and 2017.

\footnotetext{
Authors' contributions

$\mathrm{JO}$ conceived the idea and wrote the manuscripts. RHSK, PvH, SvW, RCY and HHTP commented on previous versions of the manuscript. All authors read and approved the final manuscript.

\section{Author details}

${ }^{1}$ Resource Ecology Group, Wageningen University, Droevendaalsesteeg 3a, 6708 PB Wageningen, The Netherlands. ${ }^{2}$ Department of Biology, University of Konstanz, 78457 Constance, Germany. ${ }^{3}$ Department of Migration and Immuno-Ecology, Max Planck Institute for Ornithology, Am Obstberg 1,
} 
78315 Radolfzell, Germany. ${ }^{4}$ Centre of Wildlife Ecology, Simon Fraser University, Burnaby, BC V5A 1S6, Canada.

\section{Acknowledgements}

We are grateful to Leo Joseph and Peter Grant for their useful comments on early versions of this manuscript. We also thank the anonymous reviewer whose suggestions greatly improved the manuscript.

\section{Competing interests}

The authors declare that they have no competing interests.

\section{Funding}

This research was funded by Stichting de Eik.

Received: 20 July 2017 Accepted: 16 November 2017

Published online: 30 November 2017

\section{References}

Alcaide M, Scordato ES, Price TD, Irwin DE. Genomic divergence in a ring species complex. Nature. 2014;511:83-5

Alexander DH, Novembre J, Lange K. Fast model-based estimation of ancestry in unrelated individuals. Genome Res. 2009;19:1655-64.

Allendorf FW, Leary RF, Spruell P, Wenburg JK. The problems with hybrids: setting conservation guidelines. Trends Ecol Evol. 2001;16:613-22.

Anderson E, Thompson EA. A model-based method for identifying species hybrids using multilocus genetic data. Genetics. 2002;160:1217-29.

Angermueller C, Pärnamaa T, Parts L, Stegle O. Deep learning for computational biology. Mol Syst Biol. 2016;12:878.

Arnold ML. Evolution through genetic exchange. Oxford: Oxford University Press; 2006.

Ayres DL, Darling A, ZwickI DJ, Beerli P, Holder MT, Lewis PO, Huelsenbeck JP, Ronquist F, Swofford DL, Cummings MP. BEAGLE: an application programming interface and high-performance computing library for statistical phylogenetics. Syst Biol. 2011;61:170-3.

Baldassarre DT, White TA, Karubian J, Webster MS. Genomic and morphological analysis of a semipermeable avian hybrid zone suggests asymmetrical introgression of a sexual signal. Evolution. 2014;68:2644-57.

Barilani M, Deregnaucourt S, Gallego S, Galli L, Mucci N, Piombo R, Puigcerver M, Rimondi S, Rodriguez-Teijeiro JD, Spano S, Randi E. Detecting hybridization in wild (Coturnix c. coturnix) and domesticated (Coturnix C. japonica) quail populations. Biol Conserv. 2005;126:445-55.

Barton NH. Gene flow past a cline. Heredity. 1979;43:333-9.

Barton NH. Multilocus clines. Evolution. 1983;37:454-71.

Barton NH, Gale KS. Genetic analysis of hybrid zones. In: Harrison RG, editor. Hybrid zones and the evolutionary process. New York: Oxford University Press; 1993. p. 13-45.

Barton NH, Hewitt GM. Analysis of hybrid zones. Annu Rev Ecol Syst. 1985;16:113-48.

Beaumont MA. Approximate Bayesian computation in evolution and ecology. Annu Rev Ecol Evol Syst. 2010;41:379-406.

Beiko RG, Hamilton N. Phylogenetic identification of lateral genetic transfer events. BMC Evol Biol. 2006;6:15.

Borge T, Lindroos K, Nadvornik P, Syvanen AC, Saetre GP. Amount of introgression in flycatcher hybrid zones reflects regional differences in pre and post-zygotic barriers to gene exchange. J Evol Biol. 2005;18:1416-24

Burri R, Nater A, Kawakami T, Mugal CF, Olason PI, Smeds L, Suh A, Dutoit L, Bureš S, Garamszegi LZ. Linked selection and recombination rate variation drive the evolution of the genomic landscape of differentiation across the speciation continuum of Ficedula flycatchers. Genome Res. 2015;25:1656-65.

Corander J, Waldmann P, Marttinen P, Sillanpää MJ. BAPS 2: enhanced possibilities for the analysis of genetic population structure. Bioinformatics. 2004;20:2363-9.

Cruickshank TE, Hahn MW. Reanalysis suggests that genomic islands of speciation are due to reduced diversity, not reduced gene flow. Mol Ecol. 2014;23:3133-57.

Darriba D, Flouri T, Stamatakis A. The state of software in evolutionary biology. bioRxiv. 2015:031930.
Degnan JH, Rosenberg NA. Gene tree discordance, phylogenetic inference and the multispecies coalescent. Trends Ecol Evol. 2009;24:332-40.

Delmore KE, Hubner S, Kane NC, Schuster R, Andrew RL, Camara F, Guigo R, Irwin DE. Genomic analysis of a migratory divide reveals candidate genes for migration and implicates selective sweeps in generating islands of differentiation. Mol Ecol. 2015;24:1873-88.

Duchesne P, Bernatchez L. AFLPOP: a computer program for simulated and real population allocation, based on AFLP data. Mol Ecol Notes. 2002;2:380-3.

Durand EY, Patterson N, Reich D, Slatkin M. Testing for ancient admixture between closely related populations. Mol Biol Evol. 2011;28:2239-52.

Eaton DAR, Ree RH. Inferring phylogeny and introgression using RADseq data: an example from flowering plants (Pedicularis: Orobanchaceae). Syst Biol. 2013;62:689-706

Edwards SV, Potter S, Schmitt CJ, Bragg JG, Moritz C. Reticulation, divergence, and the phylogeography-phylogenetics continuum. PNAS. 2016;113:8025-32.

Elgvin TO, Trier CN, Tørresen OK, Hagen IJ, Lien S, Nederbragt AJ, Ravinet M, Jensen H, Sætre G-P. The genomic mosaicism of hybrid speciation. Sci Adv. 2017;3:e1602996.

Ellegren H, Smeds L, Burri R, Olason PI, Backström N, Kawakami T, Kunstner A, Makinen H, Nadachowska-Brzyska K, Qvarnström A, Uebbing S, Wolf JBW. The genomic landscape of species divergence in Ficedula flycatchers. Nature. 2012:491:756-60.

Eriksson A, Manica A. Effect of ancient population structure on the degree of polymorphism shared between modern human populations and ancient hominins. PNAS. 2012;109:13956-60.

Feder JL, Egan SP, Nosil P. The genomics of speciation-with-gene-flow. Trends Genet. 2012;28:342-50.

Fitzpatrick BM. Rates of evolution of hybrid inviability in birds and mammals. Evolution. 2004:58:1865-70.

Fitzpatrick BM. Alternative forms for genomic clines. Ecol Evol. 2013;3:1951-66.

Fogel GB. Computational intelligence approaches for pattern discovery in biological systems. Brief Bioinform. 2008;9:307-16.

Frosch C, Kraus RHS, Angst C, Allgower R, Michaux J, Teubner J, Nowak C. The genetic legacy of multiple beaver reintroductions in central Europe. PLOS ONE. 2014;9:e97619.

Fuchs J, Pons JM, Liu L, Ericson PGP, Couloux A, Pasquet E. A multi-locus phylogeny suggests an ancient hybridization event between Campephilus and melanerpine woodpeckers (Aves: Picidae). Mol Phylogenet Evol. 2013;67:578-88.

Gay L, Neubauer G, Zagalska-Neubauer M, Debain C, Pons JM, David P, Crochet PA. Molecular and morphological patterns of introgression between two large white-headed gull species in a zone of recent secondary contact. Mol Ecol. 2007;16:3215-27.

Gompert Z, Buerkle CA. A powerful regression-based method for admixture mapping of isolation across the genome of hybrids. Mol Ecol. 2009;18:1207-24.

Gompert Z, Buerkle CA. Bayesian estimation of genomic clines. Mol Ecol. 2011;20:2111-27.

Green RE, Krause J, Briggs AW, Maricic T, Stenzel U, Kircher M, Patterson N, Li $H$, Zhai WW, Fritz MHY, Hansen NF, Durand EY, Malaspinas AS, Jensen JD, Marques-Bonet T, Alkan C, Prufer K, Meyer M, Burbano HA, Good JM, Schultz R, Aximu-Petri A, Butthof A, Hober B, Hoffner B, Siegemund M, Weihmann A, Nusbaum C, Lander ES, Russ C, Novod N, Affourtit J, Egholm M, Verna C, Rudan P, Brajkovic D, Kucan Z, Gusic I, Doronichev VB, Golovanova LV, Lalueza-Fox C, de la Rasilla M, Fortea J, Rosas A, Schmitz RW, Johnson PLF, Eichler EE, Falush D, Birney E, Mullikin JC, Slatkin M, Nielsen R, Kelso J, Lachmann M, Reich D, Paabo SA. Draft sequence of the Neandertal genome. Science. 2010;328:710-22.

Grossen C, Seneviratne SS, Croll D, Irwin DE. Strong reproductive isolation and narrow genomic tracts of differentiation among three woodpecker species in secondary contact. Mol Ecol. 2016;25:4247-66.

Haasl RJ, Payseur BA. Fifteen years of genomewide scans for selection: trends, lessons and unaddressed genetic sources of complication. Mol Ecol. 2016:25:5-23.

Harr B. Genomic islands of differentiation between house mouse subspecies. Genome Res. 2006;16:730-7.

Harrison RG. Hybrid zones: windows on evolutionary process. Oxf Surv Evol Biol. 1990:7:69-129. 
Harrison RG, Larson EL. Hybridization, introgression, and the nature of species boundaries. J Hered. 2014;105:795-809.

Harrison RG, Larson EL. Heterogeneous genome divergence, differential introgression, and the origin and structure of hybrid zones. Mol Ecol. 2016;25:2454-66.

Hewitt GM. Hybrid zones—natural laboratories for evolutionary studies. Trends Ecol Evol. 1988;3:158-67.

Hey J. Isolation with migration models for more than two populations. Mol Biol Evol. 2010;27:905-20.

Hey J, Nielsen R. Multilocus methods for estimating population sizes, migration rates and divergence time, with applications to the divergence of Drosophila pseudoobscura and D. persimilis. Genetics. 2004;167:747-60.

Hey J, Chung YJ, Sethuraman A. On the occurrence of false positives in tests of migration under an isolation-with-migration model. Mol Ecol. 2015;24:5078-83.

Huson DH, Bryant D. Application of phylogenetic networks in evolutionary studies. Mol Biol Evol. 2006;23:254-67.

Jarvis ED. Perspectives from the avian phylogenomics project: questions that can be answered with sequencing all genomes of a vertebrate class. Annu Rev Anim Biosci. 2016:4:45-59.

Jarvis ED, Mirarab S, Aberer AJ, Li B, Houde P, Li C, Ho SYW, Faircloth BC, Nabholz B, Howard JT, Suh A, Weber CC, da Fonseca RR, Li JW, Zhang F, Li H, Zhou L, Narula N, Liu L, Ganapathy G, Boussau B, Bayzid MS, Zavidovych V, Subramanian S, Gabaldon T, Capella-Gutierrez S, HuertaCepas J, Rekepalli B, Munch K, Schierup M, Lindow B, Warren WC, Ray D, Green RE, Bruford MW, Zhan XJ, Dixon A, Li SB, Li N, Huang YH, Derryberry EP, Bertelsen MF, Sheldon FH, Brumfield RT, Mello CV, Lovell PV, Wirthlin M, Schneider MPC, Prosdocimi F, Samaniego JA, Velazquez AMV, Alfaro-Nunez A, Campos PF, Petersen B, Sicheritz-Ponten T, Pas A, Bailey T, Scofield P, Bunce M, Lambert DM, Zhou Q, Perelman P, Driskell AC, Shapiro B, Xiong ZJ, Zeng YL, Liu SP, Li ZY, Liu BH, Wu K, Xiao J, Yinqi $X$, Zheng QM, Zhang Y, Yang HM, Wang J, Smeds L, Rheindt FE, Braun M, Fjeldsa J, Orlando L, Barker FK, Jonsson KA, Johnson W, Koepfli KP, O'Brien S, Haussler D, Ryder OA, Rahbek C, Willersle E, Graves GR, Glenn TC, McCormack J, Burt D, Ellegren H, Alström P, Edwards SV, Stamatakis A, Mindell DP, Cracraft J, Braun EL, Warnow T, Jun W, Gilbert MTP, Zhang GJ. Whole-genome analyses resolve early branches in the tree of life of modern birds. Science. 2014;346:1320-31.

Joly S, McLenachan PA, Lockhart PJ. A statistical approach for distinguishing hybridization and incomplete lineage sorting. Am Nat. 2009;174:E54-70.

Jombart T, Devillard S, Balloux F. Discriminant analysis of principal components: a new method for the analysis of genetically structured populations. BMC Genet. 2010;11:94.

Kingston SE, Parchman TL, Gompert Z, Buerkle CA, Braun MJ. Heterogeneity and concordance in locus-specific differentiation and introgression between species of towhees. J Evol Biol. 2017;30:474-85.

Kozlov AM, Aberer AJ, Stamatakis A. ExaML version 3: a tool for phylogenomic analyses on supercomputers. Bioinformatics. 2015;31:2577-9.

Kraus RH, Wink M. Avian genomics: fledging into the wild! J Ornithol. 2015;156:1-15.

Kraus RHS, Kerstens HHD, van Hooft P, Megens HJ, Elmberg J, Tsvey A, Sartakov D, Soloviev SA, Crooijmans RPMA, Groenen MAM, Ydenberg RC, Prins HHT. Widespread horizontal genomic exchange does not erode species barriers among sympatric ducks. BMC Evol Biol. 2012;12:45.

Kubatko LS. Identifying hybridization events in the presence of coalescence via model selection. Syst Biol. 2009;58:478-88.

Lackey AC, Boughman JW. Evolution of reproductive isolation in stickleback fish. Evolution. 2017;71:357-72.

Lamichhaney S, Berglund J, Almen MS, Maqbool K, Grabherr M, MartinezBarrio A, Promerova M, Rubin CJ, Wang C, Zamani N, Grant BR, Grant PR, Webster MT, Andsersson L. Evolution of Darwin's finches and their beaks revealed by genome sequencing. Nature. 2015;518:371-5.

Lavretsky P, Engilis A, Eadie JM, Peters JL. Genetic admixture supports an ancient hybrid origin of the endangered Hawaiian duck. J Evol Biol. 2015;28:1005-15.

Leung MK, Delong A, Alipanahi B, Frey BJ. Machine learning in genomic medicine: a review of computational problems and data sets. Proc IEEE. 2016;104:176-97.

Linck EB, Hanna ZR, Sellas A, Dumbacher JP. Evaluating hybridization capture with RAD probes as a tool for museum genomics with historical bird specimens. Ecol Evol. 2017;7:4755-67.
Maddison WP. Gene trees in species trees. Syst Biol. 1997;46:523-36.

Maddison WP, Knowles LL. Inferring phylogeny despite incomplete lineage sorting. Syst Biol. 2006;55:21-30.

Martin SH, Davey JW, Jiggins CD. Evaluating the use of ABBA-BABA statistics to locate introgressed loci. Mol Biol Evol. 2014;32:244-57.

Meng C, Kubatko LS. Detecting hybrid speciation in the presence of incomplete lineage sorting using gene tree incongruence: a model. Theor Popul Biol. 2009;75:35-45.

Nadachowska-Brzyska K, Li C, Smeds L, Zhang GJ, Ellegren H. Temporal dynamics of avian populations during Pleistocene revealed by wholegenome sequences. Curr Biol. 2015;25:1375-80.

Nater A, Burri R, Kawakami T, Smeds L, Ellegren H. Resolving evolutionary relationships in closely related species with whole-genome sequencing data. Syst Biol. 2015;64:1000-17.

Nielsen EE, Bach LA, Kotlicki P. HYBRIDLAB (version 1.0): a program for generating simulated hybrids from population samples. Mol Ecol Notes. 2006;6:971-3.

Nosil P, Feder JL. Widespread yet heterogeneous genomic divergence. Mol Ecol. 2012;21:2829-32.

Ottenburghs J, Ydenberg RC, van Hooft P, van Wieren SE, Prins HHT. The avian hybrids project: gathering the scientific literature on avian hybridization. Ibis. 2015:157:892-4.

Ottenburghs J, van Hooft P, Van Wieren SE, Ydenberg RC, Prins HHT. Birds in a bush: toward an avian phylogenetic network. Auk. 2016;133:577-82.

Ottenburghs J, Megens H-J, Kraus RHS, van Hooft P, van Wieren SE, Crooijmans RPMA, Ydenberg RC, Groenen MAM, Prins HHT. A history of hybrids? Genomic patterns of introgression in the True Geese. BMC Evol Biol. 2017;17:201.

Oyler-McCance SJ, Oh KP, Langin KM, Aldridge CL. A field ornithologist's guide to genomics: practical considerations for ecology and conservation. Auk. 2016;133:626-48.

Pamilo P, Nei M. Relationships between gene trees and species trees. Mol Biol Evol. 1988;1988(5):568-83.

Parchman TL, Gompert Z, Braun MJ, Brumfield RT, Mcdonald DB, Uy JAC, Zhang G, Jarvis ED, Schlinger BA, Buerkle CA. The genomic consequences of adaptive divergence and reproductive isolation between species of manakins. Mol Ecol. 2013;22:3304-17.

Parsons TJ, Olson SL, Braun MJ. Unidirectional spread of secondary sexual plumage traits across an avian hybrid zone. Science. 1993;260:1643-6.

Payseur BA. Using differential introgression in hybrid zones to identify genomic regions involved in speciation. Mol Ecol Resour. 2010;10:806-20.

Payseur BA, Rieseberg LH. A genomic perspective on hybridization and speciation. Mol Ecol. 2016;25:2337-60.

Pease JB, Hahn MW. Detection and polarization of introgression in a five-taxon phylogeny. Syst Biol. 2015;64:651-62.

Pinho C, Hey J. Divergence with gene flow: models and data. Annu Rev Ecol Evol Syst. 2010;41:215-30.

Poelstra JW, Vijay N, Bossu CM, Lantz H, Ryll B, Muller I, Baglione V, Unneberg P, Wikelski M, Grabherr MG, Wolf JBW. The genomic landscape underlying phenotypic integrity in the face of gene flow in crows. Science. 2014;344:1410-4.

Pritchard JK, Stephens M, Donnelly P. Inference of population structure using multilocus genotype data. Genetics. 2000;155:945-59.

Raj A, Stephens M, Pritchard JK. fastSTRUCTURE: variational inference of population structure in large SNP data sets. Genetics. 2014;197:573-89.

Raposo do Amaral F, Albers PK, Edwards SV, Miyaki CY. Multilocus tests of Pleistocene refugia and ancient divergence in a pair of Atlantic forest antbirds (Myrmeciza). Mol Ecol. 2013;22:3996-4013.

Rheindt FE, Edwards SV. Genetic introgression: an integral but neglected component of speciation in birds. Auk. 2011;128:620-32.

Rheindt FE, Fujita MK, Wilton PR, Edwards SV. Introgression and phenotypic assimilation in Zimmerius flycatchers (Tyrannidae): population genetic and phylogenetic inferences from genome-wide SNPs. Syst Biol. 2014;63:134-52.

Ruegg K, Anderson EC, Boone J, Pouls J, Smith TB. A role for migration-linked genes and genomic islands in divergence of a songbird. Mol Ecol. 2014;23:4757-69.

Saetre GP, Borge T, Lindell J, Moum T, Primmer CR, Sheldon BC, Haavie J, Johnsen A, Ellegren H. Speciation, introgressive hybridization and nonlinear rate of molecular evolution in flycatchers. Mol Ecol. 2001;10:737-49. 
Saetre GP, Borge T, Lindroos K, Haavie J, Sheldon BC, Primmer C, Syvanen AC. Sex chromosome evolution and speciation in Ficedula flycatchers. Proc R Soc B. 2003;270:53-9.

Schaefer J, Duvernell D, Campbell DC. Hybridization and introgression in two ecologically dissimilar Fundulus hybrid zones. Evolution. 2016;70:1051-63.

Seneviratne SS, Davidson P, Martin K, Irwin DE. Low levels of hybridization across two contact zones among three species of woodpeckers (Sphyrapicus sapsuckers). J Avian Biol. 2016;47:887-98.

Smyth JF, Patten MA, Pruett CL. The evolutionary ecology of a species ring: a test of alternative models. Folia Zool. 2015;64:233-44

Spurgin LG, Wright DJ, van der Velde M, Collar NJ, Komdeur J, Burke T, Richardson DS. Museum DNA reveals the demographic history of the endangered Seychelles warbler. Evol Appl. 2014;7:1134-43.

Taylor SA, White TA, Hochachka WM, Ferretti V, Curry RL, Lovette I. Climatemediated movement of an avian hybrid zone. Curr Biol. 2014;24:671-6.

Tegelström H, Gelter HP. Haldane rule and sex biased gene flow between two hybridizing flycatcher species (Ficedula albicollis and F. hypoleuca, Aves, Muscicapidae). Evolution. 1990;44:2012-21.

Than C, Nakhleh L. Species tree inference by minimizing deep coalescences. PLoS Comput Biol. 2009;5:e1000501.

Toews DPL, Campagna L, Taylor SA, Balakrishnan CN, Baldassarre DT, DeaneCoe PE, Harvey MG, Hooper DM, Irwin DE, Judy CD, Mason NA, McCormack JE, McCracken KG, Oliveros CH, Safran RJ, Scordato ESC, Faust Stryjweksi K, Tigano A, Uy JAC, Winger BM. Genomic approaches to understanding population divergence and speciation in birds. Auk. 2016:133:13-30.

Turner TL, Hahn MW, Nuzhdin SV. Genomic islands of speciation in Anopheles gambiae. PLoS Biol. 2005;3:1572-8.
Via S. Divergence hitchhiking and the spread of genomic isolation during ecological speciation-with-gene-flow. Philos Trans R Soc Lond B Biol. 2012;367:451-60.

Vijay N, Bossu CM, Poelstra JW, Weissensteiner MH, Suh A, Kryukov AP, Wolf JBW. Evolution of heterogeneous genome differentiation across multiple contact zones in a crow species complex. Nat Commun. 2016;7:13195

Walsh J, Rowe RJ, Olsen BJ, Shriver WG, Kovach Al. Genotype-environment associations support a mosaic hybrid zone between two tidal marsh birds. Ecol Evol. 2016;6:279-94.

Wang LY, Luzynski K, Pool JE, Janousek V, Dufkova P, Vyskocilova MM, Teeter KC, Nachman MW, Munclinger P, Macholan M, Pialek J, Tucker PK. Measures of linkage disequilibrium among neighbouring SNPS indicate asymmetries across the house mouse hybrid zone. Mol Ecol. 2011;20:2985-3000

Wen D, Yu Y, Nakhleh L. Bayesian inference of reticulate phylogenies under the multispecies network coalescent. PLoS Genet. 2016;12:e1006006.

Wolf JB, Ellegren H. Making sense of genomic islands of differentiation in light of speciation. Nat Rev Genet. 2017;18:87-100.

Wu Cl. The genic view of the process of speciation. J Evol Biol. 2001;14:851-65.

Yeung CKL, Tsai PW, Chesser RT, Lin RC, Yao CT, Tian XH, Li SH. Testing founder effect speciation: divergence population genetics of the spoonbills Platalea regia and P. minor (Threskiornithidae, Aves). Mol Biol Evol. 2011:28:473-82.

Yu Y, Barnett RM, Nakhleh L. Parsimonious inference of hybridization in the presence of incomplete lineage sorting. Syst Biol. 2013;62:738-51.

Zarza E, Faircloth BC, Tsai WL, Bryson RW Jr, Klicka J, McCormack JE. Hidden histories of gene flow in highland birds revealed with genomic markers. Mol Ecol. 2016:25:5144-57.

\section{Submit your next manuscript to BioMed Central and we will help you at every step:}

- We accept pre-submission inquiries

- Our selector tool helps you to find the most relevant journal

- We provide round the clock customer support

- Convenient online submission

- Thorough peer review

- Inclusion in PubMed and all major indexing services

- Maximum visibility for your research

Submit your manuscript at www.biomedcentral.com/submit
O Biomed Central 